\title{
Hoarseness of Voice: Presentation of Neglected Denture Esophagus
}

\section{Sunil Kumar, Devendra Bahadur Singh}

\begin{abstract}
Aspiration or ingestion of a foreign body is well-known in the pediatric as well as in the adult population. The majority of esophageal foreign bodies pass through the gastrointestinal tract without causing complications. However, large sharp foreign bodies like dentures and meat bones can get deeply embedded in the wall leading to life-threatening complications. We report a case of a neglected denture in a 55-year-old patient who presented with an unusual complaint as hoarseness of voice and was removed with the help of rigid esophagoscope.
\end{abstract}

Keywords: Hoarseness of voice, Denture, Rigid esophagoscopy.

How to cite this article: Kumar S, Singh DB. Hoarseness of Voice: Presentation of Neglected Denture Esophagus. Int J Prosthodont Restor Dent 2013;3(1):30-32.

Source of support: Nil

Conflict of interest: None

\section{INTRODUCTION}

Foreign body ingestion is a common problem in pediatric ${ }^{1}$ as well as in adult population. Most common foreign bodies in pediatric age group are coins, ${ }^{2}$ while in adults, bones and boluses of meat have commonly been reported. ${ }^{3}$ Diagnosis of denture impaction is challenging as patients often present with vague symptoms and are unaware of swallowing their dentures. Physical examination may be normal in as many as $90 \%$ of patients with esophageal impaction. Rare findings on physical examination such as fever, palatal abrasion and subcutaneous emphysema are suggestive of esophageal perforation. Rarely, patient may present with change in voice due to impaction of denture or sharp foreign bodies at the level of pyriform sinus which causes restricted vocal cord mobility. Accurate radiological localization of the site of impaction may be difficult even with the use of contrast medium, because most dentures are made of radiolucent acrylic resins. Over $90 \%$ of the foreign bodies pass uneventfully through the gastrointestinal tract. ${ }^{4}$ Rigid esophagoscopy and endoscopic removal is commonly used to extract foreign body, with success rate $80 \% .{ }^{5}$ Artificial dentures because of their shape, sizes, rigidity and pointed edges get frequently impacted in the esophagus and are difficult to retrieve endoscopically. ${ }^{6}$ The most commonly used method for removal of impacted foreign bodies in the esophagus is rigid esophagoscopy. Impaction causes serious complications as esophageal perforation, mediastinitis, fistula formation, airway obstruction leading to a high morbidity and mortality. ${ }^{7}$ Because of high chances of complication in such type of foreign bodies, a rapid and accurate diagnosis, together with subsequent treatment either in the form of esophagoscopic or surgical removal is required. ${ }^{8}$

\section{CASE REPORT}

A 55-year-old patient presented to ENT Outpatient Department with the complaints of mild throat discomfort for 7 days back for which he consulted the local practitioner and got some symptomatic improvement after taking conservative treatment. For last 3 days, patient had hoarseness of voice and mild pain in the neck. There was no history of fever, drooling of saliva and breathlessness. On examination, the patient was of average built. ENT and head and neck examination revealed mild tenderness over the neck. Indirect laryngoscopy showed decreased movement of the right vocal cord with pooling of saliva in pyriform sinus. Other examinations including chest $\mathrm{X}$-ray were normal. On detailed examination, patient gave history of missing denture but was not sure about accidental ingestion. With the provisional diagnosis of foreign body (denture) esophagus, flexible esophagoscopy was done and foreign body visualized (Fig. 1) but could not be retrieved because of impaction. Rigid esophagoscopy performed under general anesthesia revealed artificial denture impacted at cricopharynx level. The large flange of the denture was impacted on medial wall of pyriform sinus which was dislodged carefully and denture was removed safely (Fig. 2). Nasogastric tube was inserted as there was mucosal

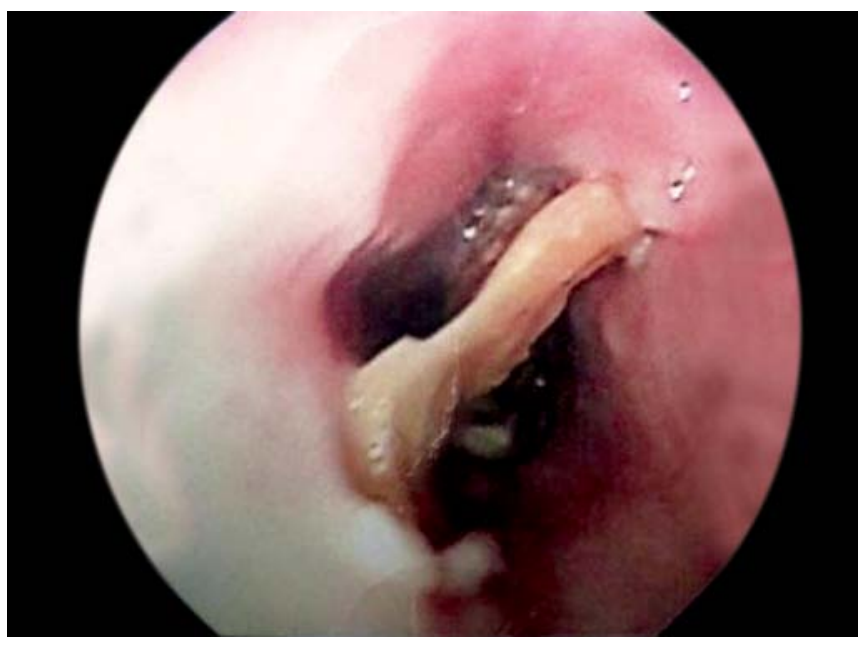

Fig. 1: Foreign body (denture) impacted at the level of pyriform sinus 


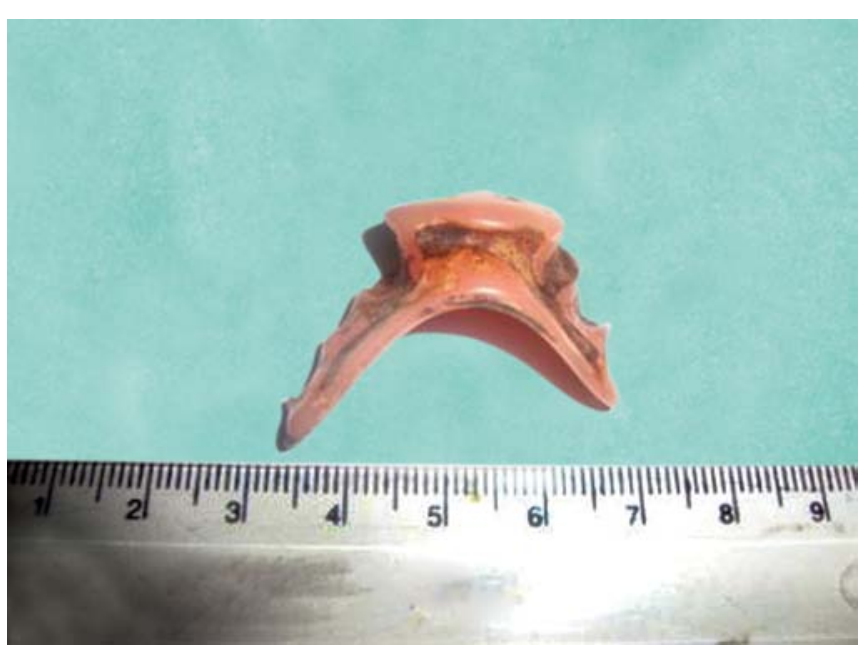

Fig. 2: Foreign body (denture) after removal

ulceration at the site of impaction. Postoperative period was uneventful and patient was discharged with normal voice after 5 days. Patient was followed-up after 15 days and there was no complaint related to deglutition or voice. Patient was referred to department of prosthodontics for a new prosthesis.

\section{DISCUSSION}

Aspiration or ingestion of a foreign body has frequently been in the adult population. In the elderly population, history of wearing artificial denture is one of the most important concerns and it accounts for most esophageal foreign bodies. ${ }^{9}$ Decreased sensation of the oral cavity due to artificial dentures and the poor motor control of the laryngopharynx increase the risk of accidental denture ingestion. ${ }^{10}$ Psychiatric and mentally retarded patients have a high risk of denture ingestion. ${ }^{11}$ Accidental ingestion usually occurs due to trauma, intoxication, loss of consciousness or sleep, so there may not be a definite history of ingestion. ${ }^{12}$ It is important to recognize that ill-fitting and damaged dentures constitute a risk factor for accidental ingestion as does sleeping with dentures left in situ. Therefore, it is important to discourage patients from wearing the dentures while asleep and from wearing either ill-fitting or damaged dentures. Careful history and examination is essential in all cases of foreign body injury irrespective of the age and presenting symptoms, as the shape and size of the foreign bodies complicates their impaction and removal. ${ }^{13}$ Following foreign body ingestion, patients usually present with dysphagia (92\%) and tenderness of the neck $(60 \%) .{ }^{14}$ Other symptoms include: inability to swallow oral secretions, throat discomfort, excessive salivation, sensation of chest pressure, laryngeal irritation and regurgitation of undigested food. Rarely, there may been signs and symptoms of mechanical pressure as in our case. Pooling of saliva in pyriform sinus on indirect laryngoscopy is an important sign of some obstructive pathology in esophagus. Denture in the esophagus can cause mucosal inflammation, ulceration and perforations leading to severe infections such as mediastinitis, deep neck abscess, aspiration and pleural empyema. Other complications reported are scarring, obstruction and fistulization. ${ }^{15}$ The radiolucent base polymethylmethacrylate makes radiological localization almost impossible. Even the porcelain and plastic artificial dentures are difficult to localize on plain radiographs. It is difficult to localize the site of impacted denture by X-ray if there is no wire in it. To some extent, radiolucent dentures can be localized by fluoroscopy after asking the patient to swallow a barium-soaked cotton wool which gets caught at the site of esophageal impaction. Radiological imaging specially chest X-ray can be helpful in localization of the exact site of radiopaque foreign body. Computed tomography scan is especially helpful in impacted dentures with complications. Because of their rigidity, large size, irregular and uneven edges, impacted dentures are prone to produce lacerations during endoscopic removal. ${ }^{16} \mathrm{~A}$ vigorous attempt at removal is avoided in the presence of pus, slough or bleeding, which indicates significant impaction or intramural perforation. Extraction of an impacted denture via esophagotomy can be undertaken under direct vision with use of shear forceps ${ }^{17}$ After flexible esophagoscopy, rigid esophagoscopy under general anesthesia should be the done as a next step. However, disimpaction may be impossible even with the greater mechanical advantage of rigid tools particularly when treatment has been delayed. Specially designed cutting forceps to divide dental plates or bones into smaller pieces and aid its maneuverability have been described. However, passage of such a robust shear through the rigid esophagoscope may almost completely obliterate the lumen and the view, limiting its efficacy.

\section{CONCLUSION}

The experience of this present case illustrates that the artificial denture rarely may present as change in voice because of decreased vocal cord mobility. Thorough clinical history, examination even in cases of negative history is most important in cases of suspected artificial denture ingestion. Rapid and accurate diagnosis with subsequent surgical intervention may decrease the morbidity and mortality in such type of cases.

\section{REFERENCES}

1. Shivakumar AM, Naik AS, Prashanth KB, Yogesh BS, Hongal GF. Foreign body in upper digestive tract. Indian J Pediatr 2004 Aug; 71(8):689-693. 
2. Yang CY. The management of ingested foreign bodies in the upper digestive tract: a retrospective study of 49 cases. Singapore Med J 1991 Oct;32(5):312-315.

3. Güitrón A, Adalid R, Huerta F, Macías M, Sánchez-Navarrete M, Nares J. Extraction of foreign bodies in the esophagus: experience in 215 cases. Rev Gastroenterol Mex 1996 JanMar;61(1):19-26.

4. Passey JC, Meher R, Agarwal S, Gupta B. Unusual complication of ingestion of a foreign body. J Laryngol Otol 2003 Jul;117(7):566-567.

5. Han S, Kayhan B, Dural K, Koçer B, Sakinci U. A new and safe technique for removing cervical esophageal foreign body. Turk J Gastroenterol 2005 Jun;16(2):108-110.

6. Dalvi AN, Thapar VK, Jagtap S, Barve DJ, Savarkar DP, Garle MN, Shukla AP. Thoracoscopic removal of impacted denture: report of a case with review of literature. J Minim Access Surg 2010 Oct;6(4):119-121.

7. Akazawa Y, Watanabe S, Nobukiyo S, Iwatake H, Seki Y, Umehara T, Tsutsumi K, Koizuka I. The management of possible fishbone ingestion. Auris Nasus Larynx 2004 Dec;31(4):413416.

8. de Lucas EM, Ruiz-Delgado ML, García-Barón PL, Sádaba P, Pagola MA. Foreign esophageal body impaction: multimodality imaging diagnosis. Emerg Radiol 2004 Feb;10(4):216-217.

9. Sittitrai P, Pattarasakulchai T, Tapatiwong H. Esophageal foreign bodies. J Med Assoc Thai 2000 Dec;83(12):1514-1518.

10. Toshima T, Morita M, Sadanaga N, Yoshida R, Yoshinaga K, Saeki H, Kakeji Y, Maehara Y. Surgical removal of a denture with sharp clasps impacted in the cervicothoracic esophagus: report of three cases. Surg Today 2011 Sep;41(9):1275-1279.

11. de Ruiter MH, van Damme PA, Drenth JP. Serious complications following removal of an ingested partial denture. Ned Tijdschr Geneeskd 2007 Jan 20;151(3):194-197.
12. Firth AL, Moor J, Goodyear PW, Strachan DR. Dentures may be radiolucent. Emerg Med J 2003 Nov; 20(6):562-563.

13. Adhikari P, Pradhananga RB, Limbu TR, Baskota DK, Sinha BK. Foreign body pyriform sinus: an unusual presentation. Nepal Med Coll J 2007 Jun;9(2):141-142.

14. Khan MA, Hameed A, Choudhry AJ. Management of foreign bodies in the esophagus. J Coll Physicians Surg Pak 2004 Apr;14(4):218-220.

15. Karaman A, Cavuşoğlu YH, Karaman I, Erdoğan D, Aslan MK, Cakmak O. Magill forceps technique for removal of safety pins in upper esophagus: a preliminary report. Int J Pediatr Otorhinolaryngol 2004 Sep;68(9):1189-1191.

16. Nwafo DC, Anyanwu CH, Egbue MO. Impacted esophageal foreign bodies of dental origin. Ann Otol Rhinol Laryngol 1980 Mar-Apr; 89(2 Pt 1):129-131.

17. Nwaorgu OG, Onakoya PA, Sogebi OA, Kokong DD, Dosumu OO. Esophageal impacted dentures. J Natl Med Assoc 2004 Oct; 96(10):1350-1353.

\section{ABOUT THE AUTHORS}

\section{Sunil Kumar (Corresponding Author)}

Assistant Professor, Department of ENT and Head and Neck Surgery King George's Medical University, Lucknow, Uttar Pradesh, India Phone: 09415820661, e-mail: drsunil_kumar123@rediffmail.com

\section{Devendra Bahadur Singh}

Assistant Professor, Department of ENT and Head and Neck Surgery Hind Institute of Medical Sciences, Barabanki, Uttar Pradesh, India 